\title{
Four-year to Eight-year Results of Vagotomy and Simple Drainage for Benign Lesser Curve Gastric Ulcer
}

\author{
H. BURGE,* M.B.E., M.B., F.R.C.S. ; A. MORTON GILL,† C.B.E., M.D., F.R.C.P. \\ C. MACLEAN, $¥$ M.D., D.M.R.D., M.R.C.P.ED. ; R. STEDEFORD, PH.D., B.M., F.R.C.S.
}

\begin{abstract}
Cummary: The results of vagotomy and simple drainage $\checkmark$ for recurrent benign lesser curve gastric ulcer are recorded. Seventy-two consecutive cases were treated from 1962 to 1965. The follow-up is therefore from five to eight years. In only two cases did the ulcer fail to heal and remain healed. Four years after operation both these had persistent ulceration and persistent gastric retention. Both have apparently been cured by gastrojejunostomy done to improve gastric drainage.
\end{abstract}

\section{Introduction}

Since 1962 we have used vagotomy and simple drainage in every patient with benign lesser curve gastric ulcer needing surgical treatment. The decision to discard gastric resection in favour of vagotomy was based on the belief that benign lesser curve gastric ulcer was caused by gastric retention, either transient or persistent. Hansky and Cain (1969) have shown that serum gastrin levels are below normal in patients with duodenal ulceration and above normal in patients with gastric ulceration; this supports the retention theory. It will be interesting to see if these findings are confirmed by other workers. The relation between duodenal ulceration with stenosis and gastric retention and lesser curve gastric ulcer has long been known (Carman, 1917). The importance of pyloric channel disease as a primary cause of benign lesser curve gastric ulcer has been dealt with in earlier papers (Burge et al. 1963; Burge, 1964; Grassi, 1967). The purpose of the present paper is to record the four-year to eight-year results of vagotomy and simple drainage in the first 72 cases operated on between March 1962 and January 1965. The earlier results of the same series have been published (Burge, 1966).

\section{Results}

Of the 72 patients two have died from causes unrelated to peptic ulceration, three have moved house and have not been traced, one has been lost to follow-up, two reported that they remain entirely free from symptoms and refuse to attend for further study, and two others also refused to attend but are reported by their general practitioners to be free from gastric trouble.

The remaining 62 patients have been interviewed and barium studies carried out. Fifty-nine have remained free from syptoms and have no evidence of gastric ulceration on barium examination in recent months. The three patients with persistent gastric ulceration make an interesting study.

\footnotetext{
* Surgeon, West London Hospital, London W.6.

Rediologist, West London Hospital, London W.6.
Resident Assistment Surgeon, West London Hospital, London W.6.
}

\section{Case Reports}

Case 1.-Barium studies in a man aged 56 revealed chronic duodenal ulceration and a giant mid-lesser curve gastric ulcer with severe gastric retention. At operation in November 1964 bilateral selective vagotomy was performed together with Finney pyloroplasty, the electrical stimulation test being used. After operation the insulin test was negative on two occasions (March 1968 and February 1969). X-ray studies: December 1964, lesser curve gastric ulcer and gastric retention; February 1965, lesser curve gastric ulcer; August 1965, lesser curve gastric ulcer; September 1967, no gastric ulcer seen; November 1967, no gastric ulcer seen; February 1968, benign lesser curve gastric ulcer; May 1968 very small lesser curve gastric ulcer. A "special" food/barium meal (Burge et al., 1969) in December 1968 showed at nine hours + gastric retention (Fig. 1). In May 1969 a similar

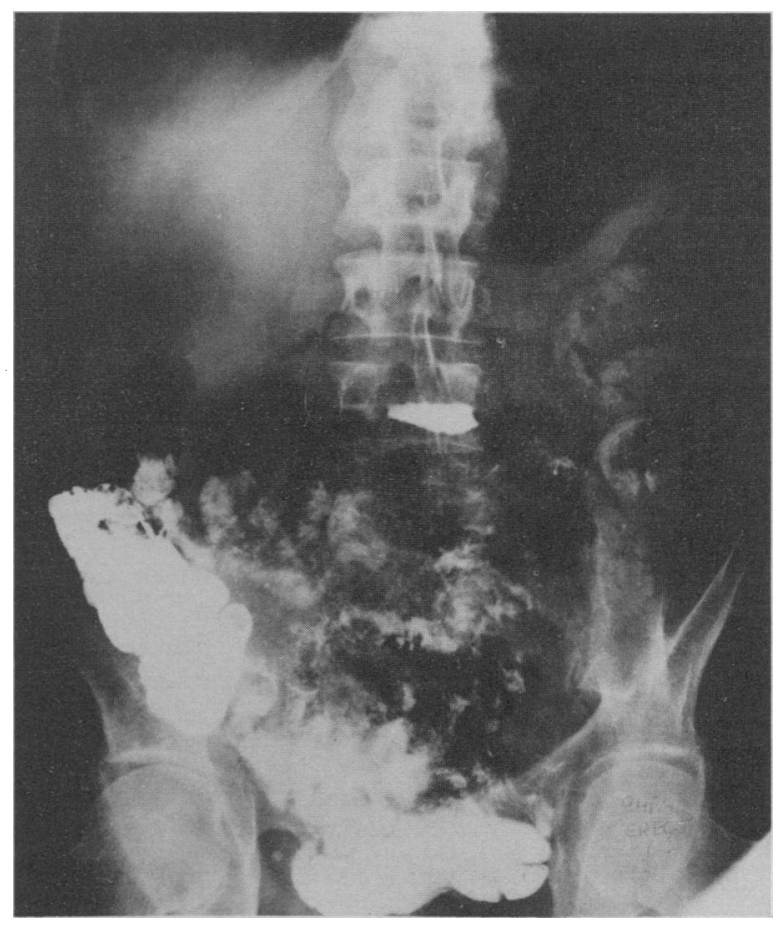

FIG. 1.-Case 1. + Gastric retention in nine-hour special meal.

film showed the stomach quite empty. This patient has remained entirely free from symptoms for over a year, and barium studies (August and December 1969) showed no evidence of gastric ulceration.

Case 2.-Barium studies in a woman aged 56 showed undoubted evidence of pyloric channel disease and a mid-lesser curve gastric ulcer. At operation in January 1965 bilateral selective vagotomy and pyloroplasty was carried out, the electrical stimulation test being used. The insulin test in June 1965 was negative. $X$-ray studies: March 1965, no gastric ulcer seen; November 1965, lesser curve gastric ulcer; May 1968, lesser curve gastric ulcer; June 1968, lesser curve gastric ulcer. A "special" food/barium meal (October 1969) showed retention in the nine-hour film (Fig. 2). This 


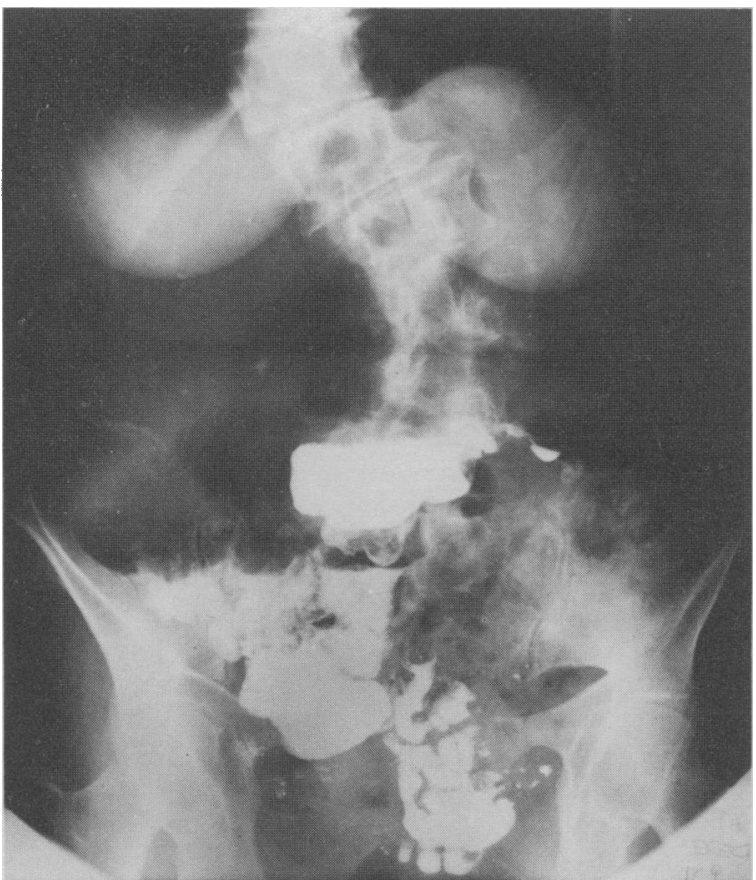

FIG. 2.-Case 2. Gastric retention in nine-hour special meal four years after selective vagotomy and pyloroplasty.

patient's ulcer healed within a few weeks after the addition of gastrojejunostomy to drain the retentioned stomach, and at the time of writing she was trouble-free.

Case 3.-Barium studies in a woman aged 78 showed duodenal ulceration and a mid-lesser curve gastric ulcer. At operation in February 1964 bilateral selective vagotomy and pyloroplasty was carried out, the electrical stimulation test being used. The insulin test in June 1969 was negative. $X$-ray studies: August 1964, lesser curve gastric ulcer; November 1964, lesser curve gastric ulcer; May 1965, lesser curve gastric ulcer; June 1965, lesser curve gastric ulcer; October 1965, no gastric ulcer seen; August 1968, lesser curve gastric ulcer. A "special" food/barium meal (January 1969) showed gastric retention in the nine-hour film (Fig. 3). This patient was treated by gastrojejunostomy to drain the retentioned antrum. The gastric ulcer healed within a few weeks and the patient has remained well since.

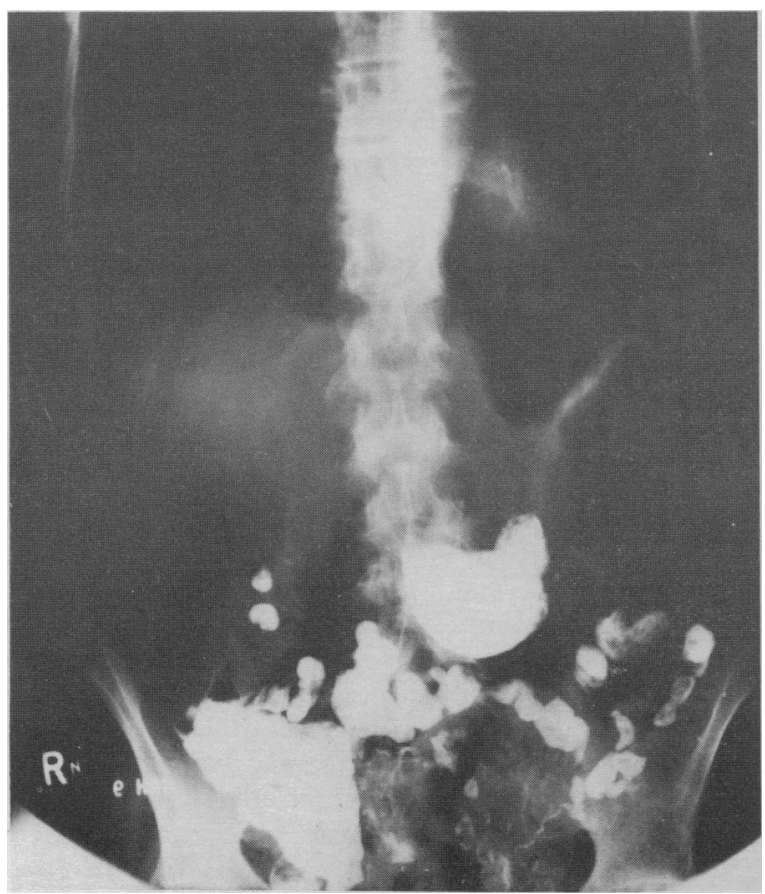

FIG. 3.-Case 3. Gastric retention in nine-hour special meal four years after selective vagotomy and pyloroplasty.

\section{Discussion}

The hypothesis that benign lesser curve gastric ulcer is caused by gastric retention (either transient or persistent) due either to duodenal ulceration or to pyloric channel disease, led us since March 1962 to use vagotomy and drainage in all patients with benign lesser curve gastric ulcer. A study of the first 72 supports this hypothesis and whether or not it is true, there is certainly sufficient evidence to suggest that vagotomy and simple drainage is the correct treatment for benign lesser curve gastric ulcer. Several centres have published their findings and the results of this operation for benign lesser curve gastric ulcer (Hendry, 1961; Hendry and Al Bahrani, 1965; Burge, 1966; Kennedy and George, 1967; De Miguel, 1968; McNeill et al., 1969). Each centre seems to have obtained very much the same results. In each a very small percentage was left with persistent gastric ulceration. These patients, it seems, have been treated usually by gastric resection, the operation of vagotomy and drainage being regarded as a failure.

Our own work suggests that when lesser curve gastric ulcer persists after vagotomy and pyloroplasty a gastroenterostomy should be added to drain the antrum more thoroughly. For this reason Dragstedt suggested that perhaps vagotomy and gastroenterostomy rather than vagotomy and pyloroplasty is the operation of choice for benign lesser curve gastric ulcer. Gastrojejunostomy performed proximal to duodenal or pyloric ring stenosis, however, is not without complications, neither is gastrojejunostomy as compared with pyloroplasty. We would choose to use vagotomy and pyloroplasty, reserving gastroenterostomy for those few cases in which it fails.

From our own studies there seems no doubt that in some cases the drainage operation may be omitted when selective vagotomy is used for benign lesser curve gastric ulcer, for in these patients there is no post-operative gastric retention and no persistent ulcer (Burge, 1970). It now remains for us to learn how to select these cases for selective vagotomy without drainage.

The importance of the completeness of vagotomy when the operation is used for gastric ulcer has not been established. Vagotomy is important, however, for pyloroplasty alone seems to fail (T. Kennedy, personal communication, 1970). If, then, gastric vagotomy is important, presumably completeness of nerve section is also important. The results of vagotomy with drainage for benign lesser curve gastric ulcer may need to be considered against the background of incomplete nerve section. This is the cause of the high recurrent ulcer rate when the operation is used for duodenal ulceration. The use of a test for completeness of nerve section at the time of operation may be as important in dealing with gastric ulcer as it is with duodenal.

A discussion on vagotomy for gastric ulcer is not complete without considering the problem of malignancy. Often when vagotomy for gastric ulcer is the subject of a paper at surgical meetings, little or no objection is raised to this form of treatment on the grounds that it may fail to cure the ulcer. Usually the only objection is that a primary malignant ulcer or secondary malignant change in a benign ulcer may be overlooked. This has in fact not happened in any of our cases since we first used the operation in 1962.

To object to vagotomy for gastric ulcer on the grounds that malignancy may be overlooked and, therefore, to advise gastric resection routinely seems to us to be wrong for the following reasons. If an ulcer is obviously benign or obviously malignant there is no problem. Only if there is doubt does a problem arise. Should such an ulcer be high on the lesser gastric curve, then gastrectomy, if it is undertaken, will be total (Fig. 4). If the ulcer after operation proves to be benign then perhaps the most serious mistake in gastric surgery has been made. The patient would have been cured either by low 


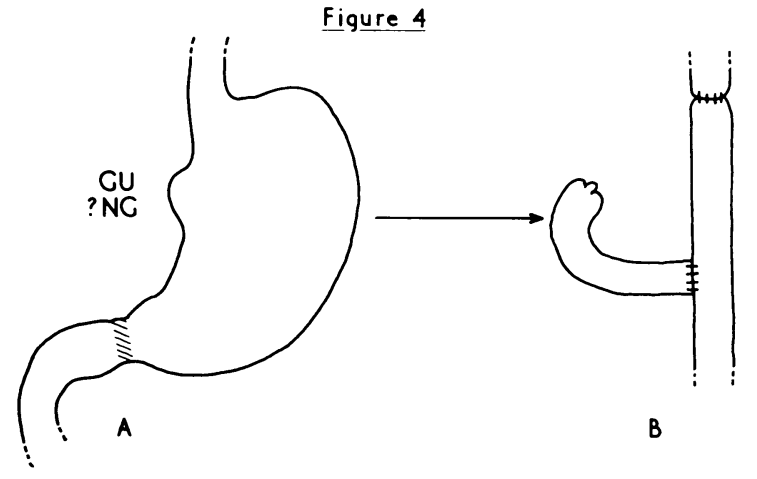

Figure 5

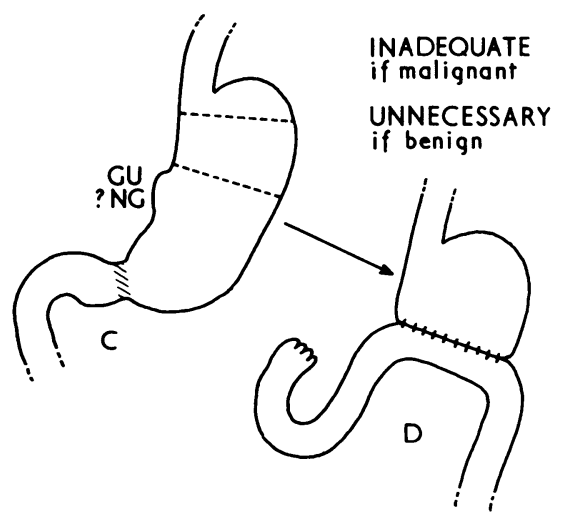

ADEOUATE if malignont A SERIOUS ERROR if benign

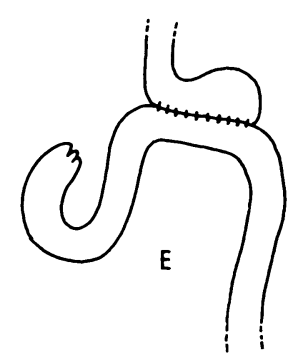

Fig. 4.-Total gastric resection for "doubtful" high lesser curve ulcer. Fig. 5.- Sites of gastric resection in "doubtful" mid-lesser curve ulcer.

gastric resection (the Kelling-Madlener operation) or preferably by vagotomy and simple drainage.

When the "doubtful" ulcer is on the mid-lesser curve the surgeon, not wanting to perform a very high gastric resection, may choose to divide the stomach a little distance above the ulcer (Fig. 5). If in this case the ulcer proves to be malignant then the operation was inadequate. If it proves to be benign then the gastric resection again was unnecessary. If in this same case the surgeon decides on a high gastric resection because he has doubt about the nature of the ulcer then again a serious error has been made, for the patient is left with very little stomach and all the disabilities and sequelae which may follow such a high resection.

How, then, is the problem to be solved? There would seem to be three ways of dealing with it. The first is to treat the patient on a medical regimen for a matter of weeks and to follow the course of healing. All benign gastric ulcers, especially large ones, are best allowed to heal before selective vagotomy is undertaken. Selective vagotomy is easier when the ulcer is completely healed. The second method is to excise the ulcer completely at the time of vagotomy and to use frozen section or await the "paraffin" report. The third method is to open the stomach and palpate the ulcer edge with the finger, and to take one or more biopsy specimens from the edge, using frozen section, or, failing this, to perform the lesser operation of vagotomy and simple drainage, then await the paraffin report. This is the method advised by Dragstedt and the one which we have chosen, so far without regret. The more carefully this method of biopsy is practised the fewer mistakes will arise. In fact there should be none. As with most mistakes in surgery the fault lies not with the method but with how well it is carried out. Probably, very rarely a mistake will arise and a malignant ulcer will be overlooked. The late results of gastric cancer are not good, and the harm done by a very occasional error must be weighed against that arising from routine gastric resection sometimes radically and unnecessarily done for benign ulcer.

\section{REFERENCES}

Burge, H. (1964). Vagotomy, p. 110. London, Arnold.

Burge, H. (1966). Annals of the Royal College of Surgeons of England, 38, 349. Burge, $H$. (1970). Proceedings of the Royal Society of Medicine, 63, 766.

Burge, H., Gill, A. M., and Lewis, R. H. (1963). Lancet, 1, 73.

Burge, H., MacLean, G., Stedeford, R., Pinn, G., and Hollanders, D. (1969). British Medical fournal, 2, 690 .

Carman, R. D. (1917). American Fournal of Roentgenology, Radium Therapy, and Nuclear Medicine, 4, 552.

De Miguel, J. (1968). Revista Española de las Enfermedades del Aparato Digestivo y de la Nutrición, 27, 24.

Grassi, G. (1967). Chirurgia Gastroenterologica, 1, 431.

Hansky, J., and Cain, M. D. (1969). Lancet, 2, 1388.

Hendry, W. G. (1961). Postgraduate Medical fournal, 37, 137.

Hendry, W. G., and Al Bahrani, Z. (1965). British fournal of Surgery, 52 588.

Kennedy, T., and George, J. D. (1967). Gut, 8, 632.

McNeill, A. D., McAdam, W. A. F., and Hutchison, J. S. F. (1969). Surgery, Gynecology and Obstetrics, 128, 91.
Qummary: Forty-three patients with an initial diagnosis of tropical splenomegaly syndrome were placed on long-term proguanil therapy. All patients who failed to respond to proguanil and who were adequately followed up developed identifiable disease, usually malignant lymphoma or chronic lymphatic leukaemia. In patients who responded to proguanil IgM values were always very high and phytohaemagglutinin (P.H.A.)-lymphocyte-transformation scores were always normal before treatment was started. In patients who failed to respond IgM values were within the normal range or below, while P.H.A.-lymphocyte-transformation scores were abnormally low. During proguanil treatment IgM values fell gradually, closely paralleling the decrease in spleen size.

- Work supported by grant from the Rockefeller Foundation.

t Research Fellow Department of Haematology, University College Hospital, Ibadan, Nigeria.

\section{Introduction}

A syndrome of chronic splenomegaly without definable aetiology is found in some people living in tropical areas and has been reported from the Congo (Charmot and Vargues, 1963), Uganda (Marsden et al., 1965), Sudan (Mustafa, 1965), Zambia (Lowenthal et al., 1966), New Guinea (Pryor, 1967) and Nigeria (Edington, 1967; Watson-Williams and Allan, 1968) and reviewed by Pitney (1968). Increased values for serum IgM in this syndrome have been reported from the Congo, Algeria, and the Ivory Coast (Charmot and André, 1964) and reviewed by (Trincẫo et al., 1966) and from New Guinea (Wells, 1968). Hepatic sinusoidal lymphocytosis was found in many of the liver biopsy specimens from Uganda and New Guinea (Marsden et al., 1965, 1967). In Ibadan it has been found that the lymphocytosis is not limited to the liver but also involves the peripheral blood and bone marrow 